\title{
Lorne Waldman Speaks
}

\begin{abstract}
Alex Zisman: How do you rate the operational implementation of the new inland determination process in terms of fairness and efficacy?

Lorne Waldman: I think that the evidence of the last few months has shown that the system is not very efficient and it is getting less efficient as time goes on. Part of that problem has to do with the big mistake that was made by the Minister when she decided to try and run two parallel systems, the backlog system to deal with the old cases and the new system to deal with the new cases. By splitting the resources of the Immigration Commission in this fashion she doomed both to failure. First, the backlog isn't going to work efficiently and effectively. Either they are going to let all the people stay or they are going to take ten years to process the cases. And the new system, because of the diversion of resources to the backlog, has been weakened as well.

The credible basis test is an extremely inefficient time-consuming mechanism for dealing with frivolous cases. The statistics suggest that over 90 per cent of the people get through

The third source of inefficiency is the second hearing stage, the full determination before the Board; it too is quite time-consuming. Recently the Board made some effort to streamline it. Even so the system has proven to be totally incapable of dealing with the number of cases that we are seeing in Canada. And the danger is that, as it becomes more backlogged, the temptation to abuse the system becomes greater. Many of us are now

\section{The is an extremely inefficient time-consuming mechanism for dealing with \\ frivolous cases.} credible basis test
\end{abstract} the first stage hearing; yet this hearing, even in conceded cases, takes many resources - lawyers paid by Legal Aid and by the Federal Government, Immigration officers, interpreters, adjudicators, Immigration and Refugee Board members. All these people have to be brought together for what is essentially a useless procedure that is only effectively weeding out a very small percentage of the cases. Contested credible basis cases are much more inefficient; they tend to go on session after session after session. I have seen a hotly contested one go on for five, six, seven sessions. Of course, every time you adjourn, it takes two or three months to reconvene.

The first stage is very inefficient and we might as well eliminate it. beginning to fear that we will see a rise of abusive claims over the next months, claims from non-refugee producing countries.

So, from an efficiency point of view, the system is not at all working. I think if you talk to Immigration officials they would agree and, in fact, would rate the system even lower that many of the refugee advocates.

From the point of view of fairness, Mr. Fairweather and the Board members point to the very high acceptance rate. That is true. In general terms, the system has proved to be extremely generous. I think that is a product to a large extent of the fact that most of the people are coming from refugee-pro- ducing countries. Having said that, there are many areas in which mistakes can be made. At the credible basis stage it is especially critical that the decision-makers understand that it is a minimum threshold test. We have seen many cases where ministerial intervention has been necessary because of the misapplication of the credible basis test. The credible basis test is a difficult legal concept to apply correctly and we perceive that many of the adjudicators who apply the test have had great difficulty. The Board members as well. In addition, when the adjudicators and Board members attempt to apply the definition of Convention refugee, in many cases they seem to have problems with understanding the concepts. Many of the decision-makers, who are being called upon to apply complex legal definitions, just don't have the capacity to do that.

The other major failure of the system with respect to fairness has been, of course, the absence of an appeal on the merits in terms of rejected cases. The application for leave to apply or leave to appeal to the Federal Court, depending on which stage, is a very cumbersome and time-consuming legal process which takes a lot of time, energy and expertise. And it is only effective in checking the most flagrant legal errors, because it is not possible to attack errors of fact but only errors of law. The effect of that has been that, in many cases, the appeal mechanism available to correct negative decisions has not been satisfactory. And the effect of that in turn has been the need for ministerial intervention in many cases.Unfortunately, ministerial intervention cannot replace an effective appeal on the merits in these types of cases.

So I think that those seem to be the major failings of the system - the lack of an effective appeal, the quality of 


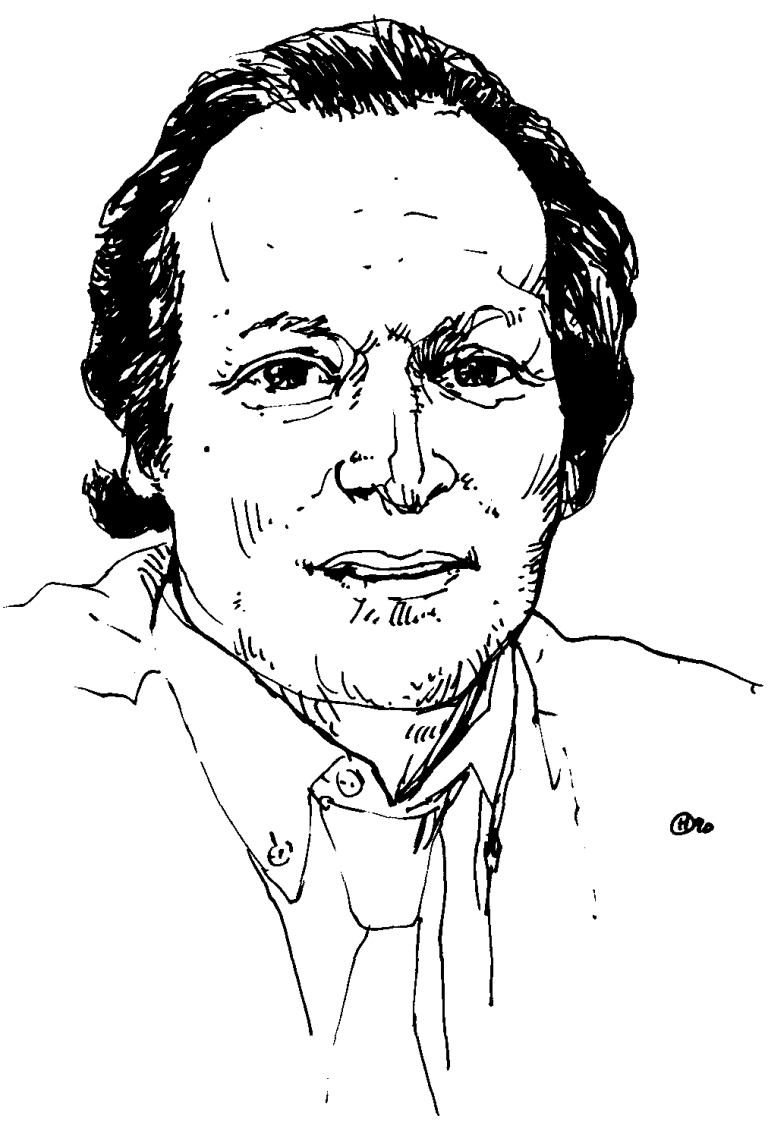

Lorne Waldman: "From an efficiency point of view, the system is not at all working."

the decision-makers, and the misapplication of the credible basis test at the first level. So, from a fairness point of view, although the system in general has been fair, even generous, many mistakes have been made and continue to be made. And there aren't sufficient checks on mistakes. The ultimate and only real check in the system is the ministerial intervention and that is subject to political interference and political considerations.

AZ: So what do you suggest should be done in order to have a more efficient determination system in place?

LW: Well, let's look at both of those questions again.

What should be done to make the system more efficient?

I think one of the most obvious things would be to eliminate the credible basis test in all cases except where the claims are manifestly unfounded.
Instead of having a hearing in all the cases, the Commission would opt to only hold credible basis hearings in cases where they felt they were serious reasons to doubt the claim and that it was really a manifestly unfounded one. Then the credible basis stage would serve its purpose, which is to serve as a check against manifestly unfounded claims. So, eliminate the credible basis stage, except in those cases which are manifestly unfounded and streamline the second stage. Those are steps that could be taken to save the system from collapse.

Unfortunately many of us doubt whether there is the political will to take the steps that are necessary.

Another step, from a practical point of view, is to scrap the backlog program. You can't have an effective system as long as you have the backlog progam because it is just taking too many resources at every level lawyers, interpreters, Immigration officials, adjudicators, Board members. We all need to save the new system from collapse, because, if the new system collapses, the backlash this time around would be far greater than what it was in 1987. The consequences will not only be negative for refugees when the government tries to introduce more restrictive legislation to deal with the crisis, but it will be a negative backlash that will affect our society, the values in our society, the generosity of our society. On a broader level it will affect race relations, things like that. So, I think we should do everything in our power to avoid a backlash. And I genuinely fear that, unless something is done quickly, the system will collapse and there will be a very serious backlash and the results of that backlash will be felt for a long time.

AZ: The Government refuses as a matter of principle to scrap the backlog; and the Minister, in spite of all the negative reports and projections, thinks that she is going to clear the backlog within the prescribed period of time. Can it be done?

LW: It depends; it could be done. For example, they started on April 17 th to redo the humanitarian interview as a result of the Federal Court decision in Yhap. It depends on how those interviews are done. They can do 125 interviews per day in Toronto and a similar number in Mississauga. So if you are doing 250 cases a day, you could do over a thousand cases a week. You could finish the backlog in less than two years provided they accept the majority of people on humanitarian review.

No one knows how generous they are going to be. The guidelines are totally ambiguous. If the guidelines are applied in generous fashion and 50,60 or 70 per cent of the people are accepted, then conceivably the backlog could be cleared in two years.

I have heard the rumours that they are thinking of other ways of streamlining cases. They are encouraging case presenting officers to review files and concede. They are 
talking about dispensing with hearings and conceding through an administrative process. They are thinking of going all sorts of different ways to try and streamline the backlog process which defeats the whole purpose of having undertaken the backlog process in the beginning, since the stated motivation was to send a message to the world. Now, as the process gets more and more bogged down, they are looking desperately for ways to complete it within the time frame to save face.

But, what's the point of spending the money? The most frustrating part about it is that as long as you keep the program running, the resources that are desperately needed in the new system are used in the old system, in the backlog system, and this weakens the new system to a great extent. The answer to your question is: maybe they'll get the backlog done in two years, but by then it would probably be too late for the new system. And whether or not they'll get the backlog done in two years depends on how many corners they cut. But the more corners they cut the less sense it makes to have a backlog program.

AZ: Streamlining appears to be the way to go not only for the backlog process but also for the new determination process. What do you think of the new measures being considered to streamline the latter?

LW: I think that they are necessary measures. It is obvious that the way the system was drafted it could not possibly deal with the numbers of people that are coming in. And I think the Government has to look seriously at measures to make it look more efficient.

Those measures would be the ones I suggested before in terms streamlining the credible basis hearings and the full hearings.

The Board seems to have been more responsive to imput from the Bar in terms of expediting the process. The expedited procedure that it instituted was suggested to the Board by members of the Bar in a meeting, and was implemented as a result of these
... the resources that are desperately needed in the new system are used in the old system, in the backlog system, and this weakens the new system

suggestions after the conversations that we had. I think that there are other options that could be implemented. Dilaogue between the Board and the Bar should continue so that we could look at different ways of expediting and improving the efficiency and productivity of the Board itself. Those are necessary measures.

Unfortunately, unlike the Board, the Immigration Commission seems to be less receptive to suggestions. Ultimately, since the two stages in the

\section{In some cases, undoubtedly, the problem} is inadequate preparation and expertise on the part of the lawyer. process are interdependent, if either stage breaks down, then the whole sustem collapses.

That's what seems to be happening now. The direction has to come from the political level to the Immigration Commission to take the necessary steps to streamline the system.

There are certainly many things that could be done. We talked to officials about the different possibilities but we do not really see anything being done. One gets the sense now of a fatalistic view - that it is too late and nothing can be done. The system was doomed anyway. I mean that is the kind of message that we have been hearing from Immigration officials over the last few months. That is depressing when you think of the consequences of the collapse of the system. Yet many people seem to be waiting for it now.

AZ: Not surprisingly, inconsistencies, errors in judgement and mistakes in fact have been pointed out during the implementation of the new determination process. While Board members have been blamed for some mishaps, would it be fair to say that poor planning and preparation displayed by some lawyers have also compounded these problems?

LW: All levels involved have to share the blame when a mistake is made. Sometimes it is obvious that the problem is with the Board members who are predisposed to make decisions in certain ways regardless of the quality of presentation by counsel and the quality of evidence given by the claimants. Certainly when you review cases, especially when you do appeals, you see in the appeals that there are occasions when the cases where not presented properly. That could be a problem of the client, who, despite all of the best preparation in the world, doesn't present his case well for whatever reason, because he usually is nervous or whatever. In some cases, undoubtedly, the problem is inadequate preparation and expertise on the part of the lawyer. That is certainly inevitable within the context of a system where the number of lawyers practising refugee law expanded dra- 
matically overnight, because, up until January 1989, you could count the number of lawyers who had an exclusive or almost exclusive refugee practice on four sets of hands probably. Now all of a sudden you have a Legal Aid pannel in Toronto which has several hundred lawyers on it, many of whom, when they started working, had absolutely no exposure to refugee cases.

So it is inevitable, especially at the beginning, that lots of people are going to make mistakes. It is a function of training, experience and things like that.

It is the same with the Board, As the Board members get more experience they become experts and the errors tend to go down. Having said that, some lawyers, because of their attitude, will never make good counsel for refugee claims. They don't have the sympathy or the empathy required. By the same token some of the Board members whom you see will never make good members or adjudicators because they don't seem to have the capacity to understand the complex factors that are involved in these types of cases.

AZ: You mentioned the problems of the appeal process. Could you expand on what do you perceive as the solutions in terms of a centralized review or something similar to that?

LW: The Immigration Commission's argument against an appeal on the merits has always been that we can't have a centralized appeal process, or any type of appeal process, because, if we do it is just going to delay the system too much. The reason why a system collapses is that it takes too long to process a case. If you are given the right to appeal at any stage you are going to bog the system down.

The system is already backlogged. If the person is found not to have a credible basis he must be removed quickly because that is the only way you send a message to the rest of the world. The fact is quick removal has not been taking place, but that is the philosophy.
On the other hand, the danger, of course, (especially with inexperienced decision-makers), is that there are cases in which they make mistakes: You don't often have time to correct that. How do you find the balance between the two positions. I don't pretend to have all the answers, but it seems there could be an administrative type of appeal process which could allow, let us say, someone like the Chairman of the Board to intervene in

\section{... any \\ appeal mechanism that would allow} for an appeal on merits would also have to take into account the danger of making a cumbersome system
more cumbersome.

cases that were brought to his or her attention by affidavit and to request a stay of removal or something like that and to allow a review in those cases.

It is essentially the function that the Minister performs now, but I think many of us would find it preferable if it were taken out of the political arena and put into the discretion of a tribunal or appeal board. Certainly any appeal mechanism that would allow for an appeal on merits would also have to take into account the danger of making a cumbersome system more cumbersome. I don't offer solutions. I know that there have been suggestions to have a centralized appeal in Ottawa at the Board level reviewing negative decisions. There is probably a lot of merit to that.

AZ: You alluded to the philosophy behind the 72-hour deportation clause applicable to those found not to have a credible basis What do you think of such other deterrence mechanisms as tourist and transit visas, fines for air carriers or other methods being discussed to prevent people from coming to Canada without proper documentation?

LW: Some of them are more effective than others. They all have their pros and cons. One of the most effective has been the visas, because the visas effectively prevent people from getting on the planes and coming to Canada. Of course, once you impose the visa, there is a cost of having to send visa officers over to process. But the more serious problem is that it denies genuine refugees access to Canada and puts them at greater risk. Sure, all of the other measures, the fines, etc. are effective to a certain extent, but only to a certain extent and are not completely effective in dealing with the problems. Ultimately the only effective deterrant is an efficient system that works quickly and fairly and allows a proper determination and the removal of those people who do not qualify. Everyone who has studied determination recognizes that the only real way to prevent abuse is if this type of system is working properly. Which is why there is so much danger when the system collapses.

AZ: We have seen an increasing number of refugee claimants as a result of the high percentage of successful cases. One could anticipate an annual unflux of 20 to 30 thousand Convention refugees alone. Do you think that is a fair estimate? Do you think it might push or influence the government to introduce the "safe third country" provision?

LW: There are two separate questions there. The first point is, I don't think that is an unreasonable estimate. I think there are statistics for the first year of somewhere around 20 thou- 
sand claims with an acceptance rate probably, globally, (when you take into account all the people who abandon claims, all the people found not credible and refused at the second stage) of around 80 per cent. We are looking at around 16 thousand accepted claims and the numbers are probably going to go up. So I would say that, sure, we are looking at somewhere around 20 thousand, perhaps slightly more as times progresses.

The second point is I do not think there is anything wrong with that. I think we need more people. I think we can easily assimilate them. And I think all of the studies seem to indicate that refugees, although they may have more difficulties initially, tend to assimilate quickly and work harder and contribute.

Well, certainly we have room and a need for immigrants. Refugees can become contributing members of society quite quickly, so the fact that we are going to get 20 thousand or 25 thousand Convention refugees doesn't alarm me at all. I think it is wonderful that we can be so generous as a country.

However, bearing in mind the priorities of the Immigration Department (they have been putting more and more emphasis on economic immigration - entrepreneurs and skilled workers at the expense of refugees -, so the Immigration Commission is not happy about the thought of 20,000 Convention refugees taking spots of other immigrants), I would suggest that the pressures to introduce "third country" will grow. I know there have been pressures over a long period of time.

The question is why have they not introduced "third country" up until now. If they haven't it is because there are political considerations. It's a difficult thing to do. If you want to put the United States on the list, do you put Central American refugees on or off the list as far as the US is concerned? If you take them off then you offend your closest friend. If you put them on you offend everyone else because it is obvious that the Americans are not dealing appropriately with the Central American refugee problem. Why should the European countries, who are put on the list, accept back refugee claimants who come to Canada? They've got more claimants in Europe than we have in Canada. There are very serious logistical difficulties. I think this is one of the main reasons why we have not seen "third country" and why we may not in fact see it. It was obviously one of the key elements in the new system and one of the rea-

\section{Ultimately,} the only effective deterrant is an efficient system that works quickly and fairly and allows

$$
\begin{gathered}
\text { a proper } \\
\text { determination } \\
\text { and the removal } \\
\text { of those people } \\
\text { who do not } \\
\text { qualify. }
\end{gathered}
$$

sons why the system is collapsing is because it has to deal with a lot more claims than antipated because the "third country" was seen as a mechanism for eliminating a very large percentage of the claims.

AZ: What views do you have on the challenge of The Canadian Council of Churches to Bill C-55? What chances will this challenge have for success?

LW: I think that the Federal Court decision has substantially weakened the impact of the challenge because they have only allowed a very small percentage of the issues to go forward, the ones that deal with areas that could not be easily raised in other types of proceedings. I understand that the decision is being appealed to the Supreme Court of Canada on the issue of standing and if they get leave then there is a possibility that the Supreme Court will review the decision of the Federal Court and allow the Council to challenge more aspects of the Bill. So we hope that the Court would give leave so that the issue of public interest standing could be decided by the Court once and for all.

AZ: Regardless of any defficiencies of the new determination system, Canada appears to have arguably the fairest refugee determination record in the Western world. Is there any proof that this factor is attracting genuine refugee claimants to Canada?

LW: There is no question that it is. If you are someone in danger of persecution and are looking for a country of safe heaven, where would you go? You go to a country that has proved to be generous. And the word gets out. I mean there is no question that the acceptance rate attracts refugees

AZ: And is there going to be a backlash as a result of that?

LW: Whether or not is there a backlash I think depends on how the issue is handled. If the collapse of the system becomes a big issue in the media and everyone starts talking about the collapse and we have five or six more stories about hordes of people arriving from this or that country to parts of Canada and people start getting upset, then, sure, there will be a backlash and it will be very negative. It depends on how it is handled. The positive stories about Canada giving safe heaven to people who suffered persecution don't make news. What makes news are the bad stories about how the system isn't working. And, unfortunately, if there is a public perception that the system isn't working, then there is a serious danger that there would be a very serious backlash. There is no question about that. 